IPSI Revista de Investigación en Psicología 1998, Vol. 1, № 2, pp. 41 - 74

\title{
TEORÍA DE LAS INTERACCIONES FAMILIARES ${ }^{1}$
}

\author{
Anal Fairlie
}

\section{Dora Frisancho}

Se hace referencia al concepto de interacción o transacción familiar y a su fuente que es la red interactiva familiar, y se detiene en las interacciones triádicas sobre las cuales se ensaya una clasificación según se ponga el énfasis en el aspecto comunicacional. en el aspecto vincular o en los procesos psíquicos que implican.

Palabras clave: Interacción familiar, relación triádica..

It is madden reference to the concept of familiar interaction of transaction, to the font that is the familiar interactive net, and stops in the triadic interactions. On this triadic interaction is essayed a classification according the emphasis on the communicational aspect, on the vinculum aspect or on the psychic processes that are implied.

Key words: Familiar interaction, triadic relationship.

\footnotetext{
${ }^{1}$ Esta exposición es parte del marco teórico del Estudio de la interacción familiar en los niños problema, investigación elaborada por los autores en la UNMSM en 1992
} 


\section{GENERALIDADES}

El estudio de las transacciones o interacciones familiares adquiere prevalencia en psicología a partir de esta segunda mitad de siglo. Hasta antes, la seña epistemológica de occidente o tradicional circulaba alrededor de la idea de que la persona o el individuo se bastaba a sí mismo para explicarse en su conducta y la búsqueda científica enfilaba a escudriñar sus interiores. Ello conducía, por ejemplo, a descifrar el misterio de la esquizofrenia dentro de variables histológicas cerebrales o de fuerzas psíquicas autoimpulsadas. Ahora y desde los años cincuenta, se tiende a imponer una psicología de las relaciones, y los desórdenes esquizofrénicos parecen tener más sentido con las disfunciones relacionales de la familia y el medio. El centro epistemológico se traslada del individuo al socius, aunque en terapia familiar este factor social es reducido a la familia. El viraje es fruto del influjo de las concepciones marxistas que, desde el siglo pasado, enfatizan la importancia del medio como fuente del comportamiento individual, y ya sin poder eludir esa dirección, nuestros estudiosos occidentales acuñan elaboraciones de interés que intentan desbrozar el complejo mundo de las determinaciones sociales tomando parcialmente las que proceden sólo de la familia. Desde entonces, diferentes corrientes de estudio enriquecen los nuevos conceptos relacionales y difunden términos específicos como «doble ligadura», «triangulación», «simbiosis» $\mathrm{y}$ «mito familiar» que obligan a centrarse conceptualmente en la familia.

Enfoques teóricos tradicionales y recientes acuden hacia este movimiento especulativo. Se advierten así los aportes del psicoanálisis, de la teoría interaccional (Mead), de la teoría existencial, de la antipsiquiatría, de la teoría de la gestalt y, últimamente, de la cibernética, teoría de los sistemas y teoría de la información o comunicación, que confluyen para iluminar algunos aspectos de la complejidad familiar. Valga como ejemplo de estos aportes algunas de las tesis de la teoría de los sistemas de Von Bertalanffy: «el hombre debe ser considerado como un «sistema de personalidad activa» y no reflejológica; el organismo es un conjunto molar 
y no molecular; la homeostasis, función de estabilidad, es cuestionada constantemente por la anamorfosis, procesos de crecimiento; las actividades simbólicas humanas permiten esta continua superación; los valores, datos psicológicos y morales, funcionan en el nivel superior de esta complejidad relacional, que en el límite es inanalizable» (Benoit, 1985, pp. 11-12).

El enlace entre síntoma o enfermedad psíquica y funcionamiento familiar derivó de la «observación de mecanismos homeostáticos en las familias de pacientes psiquiátricos, lo que llevó a la hipótesis de la familia como un sistema homeostático y, más específicamente, como un sistema gobernado por reglas. $\mathrm{Y}$ esto es así porque dichas reglas surgen con claridad si uno observa las reacciones que produce su anulación, a partir de las que se puede inferir la regla que fue violada» (Jackson, cito por Watzlawick, 1973, p. 137). Estas reglas, se entiende, no son sino las interacciones que nos ocupan.

A la familia se la observa en sus modos de vincularse, en sus maneras de comunicarse, en sus modalidades idiosincrásicas y elaboraciones típicas, tras definir sus rasgos organizativos, su estructura de conjunto, su «arquitectura» o, como también han dicho, su «biopsia de interacción». La definición de sus modelos y patrones de comportamiento sería utilizada como cartabón para establecer diferencias entre una familia y otra y entre grupos de familias, como efectivamente fue el procedimiento más generalizado en el estudio de las familias con un miembro esquizofrénico encaminado al encuentro de la génesis de esta enfermedad o de la «patología familiar en la esquizofrenia», en las décadas del 50 o 60, particularmente en Estados Unidos de Norteamérica. Actualmente ha perdido vigencia esa dirección circunscrita al mismo tiempo que siguen enriqueciéndose los estudios de la familia.

Cada vez se descubre nuevos tipos de interacción y se precisa la nomenclatura relacional sin dejar de referirlos al proceso interaccional «patológico», opuesto al «normal», dado que el objetivo central está 
signado por la terapéutica familiar. Los terapeutas de uno y otro enfoque parten del concepto de familia como entidad protectora que para cumplir su propósito mantiene dialécticamente dos tendencias indisociables: la del equilibrio u homeostasis y la del crecimiento o diferenciación, en constante afirmación y negación mutua. Identidad y desarrollo en pugna. Si un proceso se estabiliza deja de crecer y para crecer debe perder estabilidad. En el campo relacional esto se traduce en valores y contravalores, en reglas para mantener la identidad de la familia y de contrarreglas para permitir su diversificación y crecimiento. La familia sigue, como todo organismo, un proceso evolutivo entre afirmación y cambio. En este proceso hay «crisis» que plantean a la familia el paso a una nueva etapa que despierta nuevos valores y objeta los anteriores en un juego que si tiene éxito da lugar a la continuación del proceso evolutivo. Los sabios nos dicen que después de una crisis hay reorganización. De tal modo que si ésta no se produce, si los antiguos valores se mantienen firmes conservándose en estabilidad y repeliendo los contravalores por el cambio, la familia se estaciona en una posición retrógrada, que es cuando las interacciones que se han estado empleando se toman rígidas, se anquilosan y rechazan todo intento de cambio. «Como en los individuos, los estudios sobre la familia indican que la flexibilidad es sinónimo de normalidad y la rigidez, de patología» (Haley, en Zuk y Nagy, 1986, p. 43). Aquí es donde hace su aparición la enfermedad. Alguien del grupo familiar soporta la defensa de los contravalores o es el representante del cambio evolutivo y queda impregnado con estas intenciones frente al resto atrincherado en la posición conservadora. Ese miembro es conocido como «mediador» y si carece de apoyo suficiente puede pasar a la condición de «chivo expiatorio», el enfermo de la familia.

«El mediador ha sido excluído por razón de unos trastornos de comportamiento cuyos contravalores son los mismo de la familia y, quizá, más bien los de las dos familias de los abuelos. La familia como sistema oscilará entre dos organizaciones incompatibles: un sistema global donde todos los miembros han quedado unidos después del fracaso de la crisis de 
maduración, y un conjunto de dos subsistemas fijos ligados: la familia del psicótico y el psicótico» (Benoit, 1985, p. 20). De este círculo vicioso sólo podrá salirse si la intervención del medio (familia de interacción, terapia familiar, etc.) genera nuevos intercambios en la familia a fin de retomar el proceso evolutivo que se había estancado.

«Conceptualizamos el aspecto de la enfermedad mental que tratamos como una detención en el desarrollo de toda la familia. Este proceso funciona sobre principios homeostáticos, permitiendo que los familiares implicados en él puedan realizar cambios compensatorios, pero no crecer. La función del terapeuta consiste, pues, en producir el cambio desde este sistema relativamente cerrado al sistema relativamente abierto compatible con el crecimiento» (Mac Gregor, en Ackerman y J ackson, 1970, p. 58).

En el desarrollo del proceso evolutivo normal o esperado, las interacciones coadyuvan a la conquista de la nueva etapa y adquieren valor de interacciones válidas y funcionales. Si el proceso fracasa, el sistema interaccional se fija, se corporeíza afirmando la homeostasis familiar (Benoit, 1985, p. 92) Y haciendo que proliferen las manipulaciones recíprocas (Benoit, 1985, p. 68) que se concentran alrededor del enfermo. Aquí las interacciones han caducado sin perjuicio de haber sido «progresistas» en el momento anterior. Lo que da la señal de que se está produciendo el entrampamiento es la aparición del síntoma que simboliza la interacción con efecto de contravalor. «Por ejemplo, el ataque de angustia que sufre una madre al nacer su hijo está expresando la dificultad de la familia para pasar a la etapa de la crianza» (Haley, 1986, p. 34). Las interacciones que gobernaban a la pareja durante el apareamiento y el embarazo no son suficientes para enfrentar la nueva situación de padres, y por tanto deben renovarse las interacciones. En toda familia hay sectores funcionales y sectores débiles o disfuncionales; estos últimos están constituídos por interacciones homeostáticas que no pueden adecuarse a los cambios que demanda el proceso evolutivo de la familia.

Los tratadistas aseveran que por sí mismas las interacciones no tienen signo negativo ni positivo; que sean buenas o malas, retardatarias o progresistas es más producto de las circunstancias y de los momentos. A nosotros nos interesan en su mero hecho de ser interacciones, como formas 
relacionales que puedan encontrarse en las distintas familias del medio en que vivimos.

\section{NOCIÓN DE INTERACCIÓN:}

En la literatura de terapia familiar las interacciones a que nos estamos refiriendo son designadas de diversas maneras: «pautas interactivas», «transacciones familiares», «tipo de reiteración de normas», «fenómenos transpersonales», «maniobras interpersonales, «pautas de la danza familiar», «secuencias de interacción», «reacciones circulares», «procesos interpersonales», «juegos relacionales»y otras. Son expresiones o maniobras a las que se recurre reiteradamente por parte de dos o más miembros de la familia con un significado o intención.

Para la psicología familiar la interacción es lo que la actitud para la psicología individual. Las interacciones son consideradas como las unidades del sistema relacional familiar; el conjunto de ellas integra la arquitectura de la familia desde el punto de vista transaccional. Titchener $e t$ $a l$, como otros, la identifican con el término «patrón», que «es una sucesión de acciones en la que participan dos o más miembros de la familia, de carácter repetitivo, con algún grado de automatismo, y que es empleada como parte de la función adaptativa del sistema familiar... Cuando hablamos de estilo, nos referimos a la organización total y al acoplamiento de unos patrones en otros, en una adaptación familiar» (Nagy y Framo, 1988, p. 44). Aquí se alude a interacción y a sistema de interacciones en orden a unidad y composición.

Las interacciones son entendidas como rasgos detectables del comportamiento familiar, como fenómenos transaccionales que se pueden observar, aislar y registrar durante la actuación de los miembros de la familia. Algunos de estos rasgos familiares o del conjunto familiar son más acudidos por unas familias y no por otras y entonces pasan a ser típicas y caracterizan la configuración familiar, adquiriendo utilidad para definir y diferenciar a las familias entre sí. Si bien las interacciones se suceden en el 
continuo familiar, se advierte que las familias muestran más disposición de reconocer algunas como suyas y a resistir y negar otras, como es observable en las transcripciones de diálogos e intercambios grabados de que disponen los textos. Para los investigadores, el problema es siempre precisar si las interacciones que observan en una familia son las que realmente motivan el sistema de esa familia, o ésta encubre otras interacciones que no deja asomar alojo inquisidor.

«Cada familia tiene, al igual que cada persona, su propio tipo de movimiento fisiológico, crecimiento y estilo de cambio» (Brodey, en Ackerman y Jackson, 1970, p. 65).

Entre los miembros de la familia, y a través del tiempo, se va tejiendo la red interactiva familiar que es diferente de una familia a otra. En la red se descubren elementos psicomotrices, perceptivos, verbales, paraverbales, no verbales, afectivos, de aproximación, de distanciamiento, de integración, de desorganización y otros. Unos son más simbólicos, otros más prácticos y otros más expresivos e instrumentales. Abarcan a veces a dos de los miembros, a tres o a más, formando «subsistemas» que se confrontan todo el tiempo y suelen entenderse mediante códigos privativos. Las alianzas entre los miembros parecen inevitables. Por los años 50, Simmel y Mills -sin referencia a la dinámica familiar- comprobaron que un grupo de tres personas tiende a descomponerse en una coalición y una tercera parte, en la estructuración de las relaciones de poder, sugiriendo que este tercero puede derivar en chivo emisario (cita de Nagy y Framo, 1988, p. 472). Entre los miembros de la familia esto es más difícil de observar, se arregla la familia para morigerarlo y ocultarlo. Es en este sentido que MacGregor dice que las interacciones «consisten en sistemas cerrados, reverberantes, que se alimentan de la energía interna y compelen a los miembros de la familia a desempeñar interminablemente sus papeles repetitivos, lo que provoca la detención del desarrollo de todos» (Ackerman y Jackson, 1976, p. 60).

Las relaciones entre los miembros pueden ser diádicas, triádicas y más. Se asegura que la diferencia entre una situación monádica y otra diádica 
es menor o menos importante que la que hay entre relación diádica y relación triádica, porque esta última implica grupo y es mucho más compleja que las otras dos; y que esa misma diferencia es mucho menor entre la triádica y la tetrádica y las sucesivas por compartir la esencia grupal (Simmel, cit. por Zuk, 1984, p. 31). Los terapeutas familiares se inclinan a considerar que las referencias al individuo o a la mónada y aun a la diada no reflejan sustantivamente la dinámica familiar, y por eso enfatizan en analizar las relaciones triádicas. Aun tratadistas psicoanalistas y cultores de las instancias intrapsíquicas, como Framo, subrayan la necesidad de atender los conjuntos. Desde los años 70, Zuk es uno de los más que insiste en ello, y con Rubinstein afirman que «se necesitan técnicas y métodos adecuados para evaluar las transacciones observadas en la psicoterapia familiar. Se encontró que el modelo diádico de uno a uno era inadecuado, y se renunció a él como medio para estimar las transacciones. Ahora se están utilizando modelos más amplios que pueden describir y estimar los complicados procesos observados, como las coaliciones, los cismas, las alianzas, las escisiones y diversas formas de mutualidad o complementariedad» (Nagy y Framo, 1988, p. 49).

«Una concepción de la relación patógena basada triádicamente debe describir tipos de coaliciones, alianzas o camarillas que tienden a producir «patrones de huída» que, en algún nivel de tensión, producen síntomas psiquiátricos en los miembros de la familia y en otros grupos» (Zuk, 1984, pp. 31-32). La interacción triádica típica, para ese autor, es el proceso de mediación, por el cual un tercero interviene en el conflicto de otros dos en una situación que compromete circularmente a los tres, en una sola red de interacción.

Pues bien, para describir el comportamiento monádico tenemos una buena cantidad de términos psicológicos. Allport dice que en inglés hay aproximadamente 18,000 términos que designan formas distintivas y personales de comportamiento (ob. cit., p. 321) Y es posible que en castellano aumente el número. Los conceptos estrictamente diádicos como 
el de «madre esquizofrenógena» y «relación sadomasoquista» hacen un número mucho menor, y menor aún los triádicos que, por lo que estamos consultando, no llegan a la centena. En vista de que las interacciones triádicas son las que retratan mejor las relaciones familiares que son nuestro tema, vamos a afincar en ellas para aproximamos a las peculiaridades relacionales de las familias de niños y adolescentes de nuestro medio en situación problematizada. En este sentido, el nuestro es un estudio enfocado triádicamente y este enfoque lleva juntamente con las teorías de la comunicación y de los sistemas al análisis de los problemas concretos y actuales de las familias, sin detenerse en el estudio del pasado a que obligarían las dimensiones diádicas y monádicas. Resalta inmediatamente también su diferencia con la orientación psicodinámica.

Vale hacer la salvedad de que no estamos por estudiar la familia desde la perspectiva del terapeuta, si bien nos servimos de sus observaciones y descubrimientos. Nuestro fin es más general dadas las dificultades que encuentra aquella perspectiva y nuestras propias posibilidades. Los límites de este estudio no invitan a entrar en mayores disquisiciones sobre lo que se viene mencionando y sobre la familia misma que como dijimos es considerada como la institución protectora por excelencia. Dentro del ámbito de las teorías que nos guían por ahora se da por sentado que la familia es una formación «natural»o, como dicen Lidz y Fleck, «es un producto necesario de la estructura biológica del hombre». Se la define así como «la unidad social primaria, la principal fuente de seguridad del niño, y el agente básico de la socialización y de la aculturación ... es esencial para la supervivencia del niño, para su aprendizaje de las técnicas de adaptación, y para desarrollar las características de la personalidad por medio de la identificación y de otros mecanismos de internalización» (Zuk y Nagy, 1986, p. 61). Por ahora dejaremos así estas ideas que parecen no tener en cuenta que, en la forma que la conocemos, la familia es un hecho reciente, aun en el desarrollo histórico de la humanidad. Este esclarecimiento, insistimos, no está dentro de nuestros objetivos, de manera que en razón de nuestro estudio y del nivel de generalidad propuesto, 
mantendremos esta concepción de la terapéutica familiar que además tiene carácter de acepción tradicional de familia y que, según Porot, se precisa en la «cuarta» definición de Littré: «Conjunto de personas de la misma sangre, que viven bajo un mismo techo, particularmente padre, madre e hijos» (ob. cit., p. 11). Esta posición nos alivia en esta parte de entrar en precisiones demográficas (veáse, por ejemplo, Ponce, 19 p.11 Y ss.), Y quizá obligarían a decisiones desesperadas como la del empadronamiento censal de nuestro país, que ha decidido prescindir del término familia y utilizar para sus fines el de hogar. Los vínculos de sangre y de techo van a primar en el orden de familias que entren a nuestra consideración.

\section{LAS INTERACCIONES:}

Pasaremos a describir las transacciones que implican por lo menos a tres miembros de la familia, no sin antes recordar que algunas de ellas todavía son consideradas por algunos autores como esencialmente diádicas, pero que en estudios más recientes las reconocen implicando a mayor número de miembros. Es el caso, entre otras, de la simbiosis sobre la que cuidadosos análisis han establecido que liga a dos personas, pero en referencia por lo menos a una tercera, que completa el circuito triangular. «Por ejemplo, aun la simbiosis madre-hijo, la relación diádica más pura, concentrada y exclusiva dentro de la experiencia humana, no puede comprenderse cabalmente sólo en función de un sistema bilateral de madre e hijo» (Sherman, en Ackerman y Jackson, 1970, p. 33). Igualmente. Towne, Messinger y Sampson reparan en que «las relaciones simbióticas que se observan en la familia son más complicadas de lo que comúnmente se cree; envuelven siempre a una tercera persona que posee un valor esencial para el mantenimiento del sistema» (Zuk, en Nagy y Framo, 1988, p. 43). Junto a todas ellas incluiremos algunas interacciones que están dejando de mencionarse en publicaciones recientes por sus connotaciones de mezcla y confusión con otras, cosa que como veremos después sucede a 
menudo.

La relación de interacciones que expondremos debimos entresacarla de los textos y artículos que nos ha sido posible reunir, en ninguno de los cuales aparece en el conjunto que mostramos. Algunas veces, el patrón interaccional es descrito y repetido como asunto al pasar sin la debida identificación ni distinción por parte de los autores consultados, de modo que invitan a buscar entre líneas para aislarlo y optar por el término que más conviene al autor, de entre los varios que menciona entre sustantivos y adjetivos sustantivados. Asimismo, no es fácil ordenar las interacciones que hemos seleccionado entre el medio centenar reunido con más o menos sustancia descriptiva. Los significados se confunden, entrecruzan o involucran y hasta responden a diversos criterios, haciendo insegura la intención clasificatoria, aun sirviéndose del diccionario de terapia familiar sistémica. Se ha tratado de reunir las en orden a sus significados más dilatados y de modo que hagan más viable nuestro trabajo. Es así que se las ha agrupado por el énfasis que ponen en uno u otro aspecto de la actividad familiar, según veremos luego:

\subsection{Interacciones con énfasis en la comunicación:}

\section{a) Doble vínculo:}

Es una de las expresiones del comportamiento paradójico. «Describe un contexto de habituales callejones sin salida en la comunicación, impuestos unos a otros por personas que se encuentran dentro de un sistema de relación» (Hoffman, p. 29). El término fue propuesto por Bateson para definir la situación de comunicación desconcertante que lleva implícitas las siguientes condiciones: 1) una relación intensa entre las personas y una de ellas como la víctima; 2) «un mandato primario negativo» que puede tener una de las dos siguientes formas: «no hagas eso o te castigaré», o «si no haces eso, te castigaré»; 3) «un mandato secundario que está en conflicto 
con el primero en un nivel más abstracto y que, al igual que el primario, está reforzado por castigos o señales que anuncian un peligro para la supervivencia ... por lo común, mediante medios no verbales; 4) «un mandato negativo terciario que prohíbe a la víctima escapar del campo», y 5) «el conjunto completo de los ingredientes deja de ser necesario cuando la víctima aprendió a percibir su universo bajo patrones de doble vínculo. Casi cualquier parte de una secuencia de doble vínculo puede resultar entonces suficiente para precipitar el pánico o la cólera» (Bateson, 1976, p. 236-237).

Ocurre cuando, por ejemplo, una madre pide a su hijo verbalmente que obedezca a su padre, al tiempo que con una señal no verbal le insinúa que le siga desobedeciendo. Idem el mensaje emitido por un padre a su hijo tímido y dependiente: «no seas tan obediente». Watzlawick sintetiza la estructura del mensaje doble vincular en tres partes: «a) afirma algo, b) afirma algo de su propia afirmación y c) ambas afirmaciones son mutuamente excluyentes. Así, si el mensaje es una instrucción, es necesario desobedecerlo para obedecerlo; si es una definición del self o del otro, la persona así definida es esa clase de persona sólo si no lo es, y no lo es si lo es. Así, el significado del mensaje es indeterminado ... Por lo tanto, aunque el mensaje carezca de sentido desde el punto de vista lógico, constituye una realidad pragmática: el receptor no puede dejar de reaccionar a él, pero tampoco puede reaccionar a él en forma apropiada (no paradójica), pues el mensaje mismo es paradójico» (ob. cit., p. 195). El asedio de dobles vínculos se emparenta con lo que Searles distinguía como las manipulaciones inconscientes del «esfuerzo por volver loco al otro» mediante el método de hacer «actuar unas contra otras las distintas partes de la personalidad» (Benoit, p. 16).

\section{b) Comunicación paradójica:}

Es la comunicación que confunde por llevar mensajes contradictorios emitidos en niveles distintos. No es la mentira, engaño o falacia intencional sine (una deducción correcta a partir de premisas congruentes". Se 
reconocen tres tipos de paradojas:

1. Paradojas lógico-matemáticas (antinomias).

2. Definiciones paradójicas (antinomias semánticas).

3. Paradojas pragmáticas (instrucciones paradójicas y predicciones paradójicas).

Los cruces de niveles comunicativos se perciben más corrientemente en las dos últimas. La más conocida de las antinomias semánticas es la de quien afirma con respecto a sí mismo: «estoy mintiendo». Entre las paradojas pragmáticas se ha difundido la siguiente: «El barbero es un soldado a quien su capitán ordena afeitar a todos sus soldados de la compañía que no se afeitan a sí mismos, pero no a los otros»(Watzlawick, 1973, pp. 173 Y ss.). Aquí se distinguen tres elementos:

1. Una fuerte relación complementaria (oficial y subordinados);

2. Dentro del marco de esa relación, se da una instrucción que se debe obedecer, pero también desobedecer para obedecer;

3. La persona que ocupa la posición de inferioridad no puede salir fuera del marco y resolver así la paradoja haciendo un comentario sobre ella, es decir, metacomunicando acerca de ella (lo cual implicaría una insubordinación).

Una persona atrapada en tal situación se encuentra en una posición insostenible. «Se impide la elección misma, nada es posible y se pone así en marcha una serie oscilatoria autoperpetuante» (Watzlawick, 1973, p. 200).

En esta comunicación, pues, se intercalan mensajes ambiguos y doblevinculares sin dejar de aparentar una actitud protectora y consejera, como lo que se escucha corrientemente: «tienes que cambiar por tí mismo. Pero no te hablo a tí, ni soy yo el que te lo dice» o «Te estoy pidiendo desde hace tiempo que busques un oficio y sé perfectamente que eso es imposible. No eres el hijo que hubieras debido ser» (Benoit, 1985, pp. 82- 
$83)$.

\section{Mistificación:}

Interacción desarrollada por Laing, a partir del concepto marxista del mismo nombre, y para la que el autor atribuye condiciones ya vistas como la de ser una «situación paradójica», significar un «entrampamiento»y sumir en una «posición insostenible), en el marco de «esas maneras de lidiar con contradicciones". Mistificar es "confundir, ofuscar, ocultar, enmascarar lo que está ocurriendo", utilizando interpretaciones falsas en lugar de las verdaderas o planteando problemas engañosos para cubrir los reales. La persona mistificada se halla confundida pero "tal vez no se sienta así". "Es una forma de actuar sobre el otro, que sirve para la defensa y seguridad de la propia persona" (Laing en Nagy y Framo, 1988, p. 403). Su efecto perturbador no consiste tanto en poner en entredicho las partes de la personalidad --como el doble vínculo sino en promover confusión, duda y desconcierto que a menudo no se reconocen como tales (Ibid, p. 407).

"La persona mistificada es aquella a la que se le hace entender que se siente feliz o triste, independientemente de cómo se sienta; que es responsable de esto o no responsable de aquello, independientemente de cuál sea la responsabilidad que se haya echado o no sobre sí misma. Se le atribuyen capacidades o la carencia de éstas, sin referencia a ningún criterio empírico compartido acerca de lo que puedan ser o no dichas capacidades ... " (Ibid, p. 405). Para Laing, casi todo está mistificado sin que lo percibamos claramente. "Lo que llamamos realidad no es más que la estructura de la fábrica de estas alucinaciones socialmente compartidas y nuestra locura colusoria es lo que llamamos cordura" (Laing 1977, p. 65). Corrientemente, la mistificación se produce cuando por ejemplo la madre, agotada luego de la jornada, no trasmite al hijo su estado de fatiga y, por el contrario, le dice que nota que él está cansado y que seguramente quiere ir ya a la cama.

\section{Descalificación, desconfirmación:}

Tiene el sentido de desvirtuar, desautorizar, anular una definición o toma de posición. Se puede descalificar lo que uno mismo está diciendo como lo que el 
otro dice. Ejemplo del primer caso es decir: "Claro que confío en tí, pero nunca hagas nada sin consultarme". Nuevamente percibe aquí el mecanismo de afirmar algo en un nivel y refutarlo en otro. Lo mismo si a la afirmación verbal se le anula con otro mensaje analógico.

Si uno de los parientes acostumbra descalificar sus propios mensajes y los de sus familiares, éstos no tardarán en darle de su propia medicina, llenando de incertidumbre la atmósfera familiar. Los hijos que crecen en ese ambiente lo adoptan de modo natural y aprenden a lidiar entre sí en esos términos y toda la familia se halla de pronto atrapada en una forma de comunicación descalificadora.

Watzlawick la distingue del rechazo directo. En éste se apunta a la verdad o falsedad o corrección del contenido del contenido del mensaje; se rechaza lo que la persona dice o hace; pero no a la persona misma, que es a donde enfila la desconfirmación: niega a la persona su capacidad de pronunciamiento o de emitir juicio. En otras palabras, mientras que el rechazo equivale al mensaje: "Estás equivocado", la desconfirmación afirma de hecho: "Tu no existes", que es lo que sucede cuando, por ejemplo, una madre desconfirma la validez de las impresiones que narra su hijo durante una sesión terapéutica (Watzlawick, 1973, p. 87). Laing agrega: "el rechazo directo no es tangencial; no escarnece ni in valida en otras formas. No necesita ni menospreciar ni exagerar la acción original. Tampoco es sinónimo de indiferencia o impenetrabilidad." (1974, p. 95). La Hoffman cita el siguiente ejemplo:

-Paciente: ¿Me trajiste mi ropa blanca?

-Madre: ¿Cómo te sientes?

-Paciente: ¿Trajiste mi ropa blanca?

-Madre: Pareces triste.

-Paciente: Estoy perfectamente.

-Madre: ¿estás enojado conmigo?

-Paciente: Sí. (ob.cit., p. 36). 


\section{Comunicación amorfa:}

Forma de comunicación destacada por Wynne que la observa en familias de esquizofrénicos simples indiferenciados y de los "procesales" y otros cuadros severos. Se caracteriza por ser "amorfa, vaga y no dirigida ... las cosas que se dicen no son afirmadas y luego desmentidas, sino por lo contrario, nunca se enuncian con claridad suficiente como para saber cuándo las desmiente otra declaración" (Nagy y Framo, 1988, p. 354). La contradicción o la paradoja y la doble ligadura no aparecen con las precisiones que hemos visto, y lo que se registra son "expectativas vagamente definidas" que invitan al cansancio. "Naturalmente, los terapeutas se descorazonan ante los agudos sentimientos de insipidez, insustancialidad, la inerte vaguedad de la expresión y la falta de destellos que de cuando en cuando le dan sabor al trabajo con los psicóticos más vivaces y sus familias" (Ib, p. 355).

Los efectos de este tipo de comunicación se perciben en los familiares que suelen presentar problemas en el manejo del lenguaje, exentos, por otro lado, de delirios y extravagancias que acompañan otros derivados.

\section{Silencio previo a la toma de decisiones:}

Ferreira y Winter distinguieron este mecanismo con prueba de significación estadística, encontrando que las familias "anormales" guardaban silencio más tiempo y llegaban a acuerdos espontáneos más raramente que las familias control carentes de problemas. "Si a una familia anormal se le asigna la tarea de llegar a una decisión

-aunque sea placentera o divertida, carente de importancia en sus vidas o desprovista de significado, o aun si se trata de un juego-, sus miembros caen en un silencio prolongado ... la duración del lapso que demora una familia en llegar a una decisión ... requiere un período más prolongado. Ello se debe en parte a que sus miembros poseen menos información que se atrevan a intercambiar recíprocamente, y deben ser cuidadosos en la forma como la presenten; representa un procedimiento trabajoso" (Ackerman y Jackson, 1970, p. 103). 


\section{Parloteo sintomático:}

Zuk desarrolla esta interacción que la hace equivalente con la risa no relacionada con el humor y el silenciamiento que veremos luego. "El parloteo puede describirse como un embrollo verbal, sin relación con la situación pero idiosincrásicamente significativo para el individuo. Si se escucha con cuidado, se descubre que a menudo el parloteo tiene un contenido definido de fantasía o alucinación" (Zuk y Nagy, 1986, p. 130). Es similar al silencio porque "el paciente no dice nada o dice cosas que no significan nada" (Zuk, 1984, p. 37).

En las sesiones psicoterapéuticas de familia, se ha observado que el paciente recurre al parloteo cuando la madre era confrontada por el terapeuta, como maniobra distractora y de protección, para evitar el esclarecimiento del comportamiento no sólo propio sino también familiar.

\section{Risa no relacionada con el humor:}

Es mencionada también como risa "inapropiada", "inadecuada" y "caprichosa", que en las sesiones de psicoterapia familiar es observada sobretodo en los llamados miembros normales, sin vinculación alguna con el ingenio o el humor. Zuk se inclina por la explicación bergsoniana de que la risa aparece cuando se reconoce la intención de ocultar algo, y cita a Albee para quien la risa, la risa entre dientes y la sonrisa suelen utilizarse para diluir, enfatizar o negar el significado emitido.

Tiene fuerte relación con la matriz paradójica de que hemos estado hablando. "Por lo menos, hay dos niveles en que puede entenderse esta risa entre dientes. Uno es que con esta risa la madre espera reforzar el vigor de sus comentarios ... El otro nivel... puede ser una negación disimulada de sus afirmaciones" (Zuk, 1984, p. 118). 


\section{Aplicación de marbetes injustos:}

Se refiere a calificativos inapropiados que se adjudican unos miembros a otros y que pasan a tener el significado de una caracterización o nombre sustituto, tales como "retrasado", "tonto" o "el idiota de siempre". Al decir de Zuk, pueden constituir la cobertura de una relación patógena en tanto denuncian una creencia o prejuicio arraigado que tiende a hacer suponer que el destinatario del marbete está imbuido de maldad o perturbación, y en ese sentido equivale a la promoción de mitos familiares inadecuados que revelan actitudes de fondo que emergen de una sistemática patogénica familiar, tal como en un caso especial donde Zuk detecta uno de estos marbetes "como un eslabón clave en la cadena de la relación patógena que incluía a los padres y al hijo" (ob. cit., p. 172).

\section{Estrategias de silenciamiento:}

Hace referencia al hecho de guardar uno silencio, y obligar a que otro lo guarde con fines instrumentales de obtener dominio o complacencia. Suele usársele como castigo sobre alguno de los miembros por haber transgredido las normas familiares. Es un fenómeno interpersonal y circular de uso muy extendido en el intercambio social. El efecto visible es el aislamiento del miembro mediante el silencio, en cuyo objetivo los otros miembros o algunos de ellos entran en colusión, fomentándose una dinámica típica de generación de chivos expiatorios" (Zuk, 1986, p.21).

Se expresa de distintos modos, aparte del parloteo y la risa inadecuada vistos ut supra. Un modo "crudo pero eficaz" es dar al hijo que molesta un caramelo. Otro, los ademanes de dolor en el pecho y similares que se emplean cuando uno de los familiares comienza a criticar. Uno más es el tratamiento de silencio conocido como "ley del hielo" aplicado a quien "ha violado el código" y que tiene la particularidad de "utilizar el silencio para producir silencio" (Zuk, p. 95). Y otros más que incluyen el recurso de la crítica de la forma para interrumpir, distraer o dejar de abordar el contenido: "Ya te he dicho que cuando quieras decirme algo hables 
claramente" o "¿Todavía no te arreglan el diente?".

"En un ejemplo, un ataque esquizofrénico pareció haberlo causado la conducta de rechazo de un esposo que deseaba divorciarse de su mujer,' una joven que ya había sido internada dos veces en un hospital. El la trataba con "indiferencia", una variante del "tratamiento de silenciamiento". Sencillamente la ignoraba, actuando como si ella no existiera" (Zuk, 1986, p. 97).

\subsection{Interacciones con énfasis en los procesos psíquicos:}

\section{a) Proyección familiar:}

Se trata del mismo mecanismo psicodinámico de la proyección pero a nivel familiar. Según Bowen "es un fenómeno natural cuando hay condiciones favorables" y ocurre en las transacciones familiares corrientes, y es también "el mecanismo predominante de la 'esquizofrenia". Dice el autor: "Las más de las veces, el problema de los padres se proyecta sobre el hijo por la obra de la madre, mientras el padre la apoya. Ella es una persona inmadura ... que busca fuera de sí misma la causa de su ansiedad. La proyección conduce a miedos y preocupaciones por la salud y capacidad del hijo. La proyección busca pequeñas incapacidades, defectos y fracasos funcionales en el hijo; centra su atención en ellos, los agranda y exagera hasta convertirlos en graves incapacidades... Cuando "la causa de su ansiedad se localiza fuera de la madre, la ansiedad mengua. Para el niño, la aceptación de la proyección como realidad representa un precio bajo para conseguir una madre más calmada ... Los padres van de médico en médico, hasta que un diagnóstico confirma finalmente la existencia del "temido" defecto (Nagy y Framo, 1988, p. 270). Así se validan temores supuestos, se distorsiona la realidad, a la manera vista de la mistificación. El hijo necesita padres tranquilos y estables y termina por aceptar el "papel" que por fuerza le asignan sus padres, convirtiéndose en el "triádico" de la familia. "Su existencia está tan absorta en "ser para los padres", que no se ocupa en tener un "yo" propio" (Ibid, p. 268). 
La proyección familiar produce miembros "acusadores" y "autoacusadores" cuya riña evidencia la presencia del mecanismo, y pasan los miembros de uno a otro papel en mayor medida cuanto más inmadurez afecte a los miembros de la familia. La tensión y la necesidad de echar la culpa al otro es la característica del funcionamiento familiar.

\section{b) Masa familiar indiferenciada de egos:}

Bowen introduce el concepto de "diferenciación" en el análisis de las familias y lo encuentra como distintivo de las familias "maduras" en contraposición a la "in diferenciación" que caracteriza a las que tienen signos de patología, particularmente, un psicótico entre sus miembros. Cuando éstos son indiferenciados aparecen como si estuvieran en "fusión", sin límites entre unos y otros y con "una preexistente necesidad emocional de permanecer juntos" haciendo equivalencia a "un solo ego". "Me imagina un racimo fusionado de egos individuales de la familia, con una frontera común. Unos egos están complemente fusionados en la masa que otros. Algunos de ellos se sienten intensamente envueltos en la masa familiar durante la tensión emocional, y están relativamente "despegados" en otros momentos ... La fusión activa puede incluir miembros de la red de parientes cercanos o aun animales favoritos y personas que no sean parientes" (Nagy y Framo, 1988, p. 263). Es perceptible que todos ellos responden o reaccionan al unísono y hasta dan muestras de tener los mismos pensamientos. Hoffman hace comparar esta indiferenciada masa del ego familiar" al concepto de "seudomutualidad" de Wynne y al de familia "enredada" de Minuchin, términos que designan "la calidad viscosa de la familia del esquizofrénico" (ob.cit., p. 40). A eso mismo apunta la "familia resbaladiza" de Boszormenyi-Nagy (Ackerman y Jackson, 1970, p.71).

La "unicidad emocional" de estas familias, su viscosidad e impenetrabilidad ha sugerido que se llame "cerca de caucho" a los límites estrechos de que se rodea, y dentro de los cuales se defiende de todo intento de cambio. 


\section{c) Caos cognoscitivo colectivo:}

lnteracción descrita por Wynne y que en otra oportunidad y justamente con la doctora Singer lo llamó "transcurso del pensamiento transaccional". En la serie dialogal y en el contexto de las transacciones, no se entiende lo que comunica un miembro al otro, no se aprecia por el observador lo que uno le quiere decir al otro ni lo que éste responde, resultando una serie "extravagante, desarticulada y fragmentada". Sin embargo, fuera del contexto, cada cláusula emitida por uno y otro miembro es perfectamente entendible como si fueran expresiones normales y corrientes. Al decir de Shaffer, las familias que la usan tienen una "institucionalización de la fragmentación" (Nagy y Framo, 1988, p. 350), de modo que parece que se entendieran sin significados, sin hilación, incongruente, borrosa $\mathrm{y}$ fragmentadamente, al modo del psicoanalítico "proceso primario". Hace poco escuchamos a una madre y su hija que al parecer se referían a otro miembro de la familia en una sucesión de aseveraciones y preguntas que más que tener relación entre sí asemejaban dardos que iban de un sentido al otro:

-El ya no es niño pequeño.

-Pero, todos vivimos juntos.

-Puede comprarse su atari.

$-i$ y qué haces tú con tu propina?

-Es mi tío el que me da.

-¿ y porqué te pusiste a llorar?

Se habla de una suerte de subcultura de estas familias que abusan de la elipsis, pero que parecen entenderse mutuamente como bajo códigos particulares y trasmisiones de emociones y asociaciones al estilo de la pantalla Beta de Bion (Cantoni, 1984, p. 77).

\section{d) Complementaridad patológica de necesidades:}

Boszormenyi-Nagy observó que las necesidades inconscientes de los padres influyen o modelan según sus requerimientos "la 
estructura psíquica" del hijo. Dichas necesidades se internalizan como demandas del superego que el yo del niño termina por aceptar por que al hacerlo éste también satisface sus propias demandas de dependencia. "En esta situación, las necesidades se satisfacen recíprocamente; los padres y el niño alimentan mutuamente sus respectivas demandas narcisistas. La repetición de esta recíproca satisfacción de necesidades se convierte en preocupación para el niño y no logra establecer una identidad que le permitiría una existencia independiente del resto de la familia" (Nagy y Framo, 1988, p. 41). Es una interacción semejante a la proyección familiar, aunque guiada por la complementariedad.

\section{e) Divorcio emocional (o Cisma Matrimonial):}

Se asocia a la problemática de la relación entre los padres.

Bowen lo explica como un temor a la "fusión". Cuando los recién casados tienen "bajos niveles de diferenciación del yo" ocurre que "ambos cónyuges suspiran por mantener relaciones estrechas, pero tal intimidad se transforma en una fusión de los dos 'pseudoyoes" hasta formar un "yo común", en el que se borran las fronteras del ego que existe entre ellos, y hay una pérdida de individualidad en beneficio del nuevo yo. Para evitar la ansiedad de la fusión, guardan una distancia emotiva suficiente, llamada "divorcio emocional", a fin de que cada uno pueda mantener la mayor cantidad posible de "pseudoyoes" (Nagy y Framo, 1988, p. 266). Equivale a una defensa inmadura o neurótica de la propia individualidad y establecen así distintos modos de relación como de conflicto permanente o de complementariedad rígida o sadomasoquista. Zuk y Rubinstein las caracterizan como parejas que no comparten sentimientos personales muy cargados y aparentan sobrellevarse bien, así como las que congenian cuando se encuentran en medios sociales comunes y corrientes, pero no pueden tolerarse el uno al otro cuando se encuentran solos" (Nagy y Framo, 1988, p. 32). 


\section{f) Inducción de ansiedad:}

En la clínica tradicional, el término "inducción de ansiedad" fue empleado por Sullivan en el sentido de comunicarse la ansiedad de una persona a otra enlazadas por una relación emocional intensa, particularmente la de madre a hijo. Aquí adquiere más generalidad por implicar toda transacción con potencial esquizogénico o de enloquecimiento. Como en el caso de la proyección familiar de Bowen significa transferencia de estados y ánsiedades entre personas estrechamente ligadas Searles distinguía seis modos esquizogenéticos, uno de los cuales, por ejemplo, consiste en llamar constantemente la atención al pariente sobre aspectos de su personalidad en los que éste apenas repara, y en los que no cree que son representativos de su identidad, pero que pueden terminar por transformarlo (Nagy y Framo, 1988, p. 406). Laing llamaría a esto "cortina de atribuciones negativas" a través de la cual se "induce confusión en el sentido de que no se logra ver qué se está experimentando "realmente", qué se está haciendo, o lo que está ocurriendo, y no se logra distinguir qué es de lo que realmente se trata" (Ibid, p. 398). Benoit repara en el uso del imperativo paradójico para "reforzar la inducción a los aspectos patológicos de la personalidad o, en otros términos, su identidad mórbida" (ob.cit., p.87).

\section{g) Mitos y ritos familiares:}

Conjunto de creencias y rituales que expresan la idiosincrasia familiar y que se exteriorizan en formas verbales y no verbales, como el mito del linaje, el personaje imaginario o fantasma, la obligación de obsequiar, la idea del familiar exitoso, "los principios" de la familia, "tenemos la costumbre ... ", "la familia piensa ... ", etc. Ferreira definió este concepto como la "serie de creencias sólidamente integradas y compartidas por todos los miembros de la familia, que atañen a cada individuo y a su relación recíproca con los demás" pasando a formar "una parte de la imagen interna 
del grupo" que designa roles y atributos que "si bien son falsos e ilusorios, son aceptados por cada uno sin que nadie se atreva a examinarlos o desafiarlos" (Rev. Sist. Fam., Dic. 1986). Los mitos sirven para consolidar las necesidades y mantener el equilibrio familiar.

\section{h) Intercambio de disociaciones:}

Resulta de los mecanismos psicodinámicos de proyeccíon, identificación proyectiva (Bion, Klein) y exteriorización (Brodey), pero compartidos por los miembros de la familia entre sí. Wynne asevera que por este intercambio se genera "una intrincada red de apreciaciones acerca de los demás y de disociaciones respecto de uno mismo, en la que cada persona "localiza" en otro miembro de la familia la totalidad de una cualidad o un sentimiento particulares ... La concepción fija que cada persona tiene de la otra es intercambiada inconscientemente por una concepción fija que de ella misma tiene la otra persona ... Una organización que proporciona un medio para que cada individuo pueda lidiar con ideas y sentimientos que de otra manera le resultarían intolerables" (Nagy y Framo, 1988, p. 348). Es el caso del padre que es casi mantenido por su mujer y sin embargo reprueba a su hijo por no conseguir trabajo, y éste, a su vez, no repara en su dejadez y culpa a su padre de las desgracias de la familia. Cada quien ve la paja en el ojo ajeno y no la viga en el propio. A este tipo de proyección mutua, Wynne lo asemejaba al concepto sociológico de expectativas de papel recíprocas.

\section{Lucha por la identidad:}

Cada quien tiene sus necesidades de identidad que busca satisfacerlas mediante el reconocimiento de los demás. La identidad que uno necesita y presume deja entrever la existencia de una identidad real y otra ideal entre las que se desea la mínima disonancia. Si un miembro de la familia no encuentra el reconocimiento que necesita en los otros, hace su lucha para que se le vea con los valores que supone tener y culpa a los otros de miopía y desconsideración; a su vez éstos reaccionan igual y, como lo explican 
detenidamente los antropólogos Wallace y Fogelson, "comúnmente, el grupo familiar se ve atrapado en un complejo de luchas por la identidad, recíprocas" (Nagy y Framo, 1988, p. 511). Esta lucha puede ser manifiesta o latente y se vale de adjetivos, metáforas, comparaciones y otras expresiones que sirven para describir tanto a la que habla como a sus interlocutores (Ibid., p. 430).

\section{Falta de atención selectiva:}

Se diferencia de la "desatención selectiva" de Sullivan por que ésta es' fenómeno intrapsíquico en oposición a la falta de atención selectiva que es relacional' Ocurre generalmente de padres a hijos y consiste en un sistemático dejar de prestar atención a las necesidades de uno o algunos de los miembros, de modo que se alimentan sentimientos de postergación e indefensión en el camino de buscar o generar "víctimas" en la familia.

\subsection{Interacciones con énfasis en la vinculación:}

\section{a) Alianzas y coaliciones:}

Generalmente se les considera sinónimos juntamente con camarillas y triangulaciones y aluden a las uniones y separaciones entre los miembros de la familia. La junta de unos hace que se diferencien de los otros, de manera que a toda unión sigue un cisma entre los miembros de intensidad diversa. Vale, sin embargo, la diferencia que hace Haley entre alianza y coalición; la primera significa sólo la unión de dos personas por interés común independiente de una tercera persona, mientras que coalición es el proceso de acción conjunta de dos personas contra una tercera. Esto último se da sobre todo de modo encubierto y suele involucrar a generaciones distintas que, también según Haley, ocurren siempre por parejas: la coalición de un padre con su hijo determinará la "coalición contrarrestan te" del otro padre con un abuelo. Son parte de las "regularidades" de las redes familiares (Hoffman, 1977 p. 120). 


\section{b) Triangulación y triángulo perverso:}

Es el tipo más recurrido de coalición. Generalmente plantea la situación del hijo frente a sus dos padres en conflicto, el hijo pasa a ser entonces el "triángulado" (Bowen). Pero el sistema que tiende a producir patología es el "triángulo perverso" que tiene las siguientes características: 1) una de las personas es de una generación diferente de otras dos; 2) dos personas de generaciones distintas se coaligan contra la tercera, y 3) la coalición entre las dos personas es negada por ambas. "Cuando esto ocurre como un patrón repetitivo, el sistema se volverá patológico" (Halley en Zuk y Nagy, 1986, p. 34).

Con los otros miembros de la familia se forman nuevos triángulos haciéndose a veces "una terrible complejidad". "En una familia de tamaño promedio donde hay dos padres y dos hijos, y cada padre tiene a su vez dos padres, este grupo de ocho gentes puede componer 56 triángulos. Cualquier persona en la familia se ve implicada en 21 triángulos familiares simultáneamente ( $\sin$ contar a los tíos y a las tías, a los vecinos y a los patrones). Cada uno de estos 21 triángulos en los que participan los padres y los hijos implican la posibilidad de una coalición entre las generaciones ... Las múltiples vinculaciones triangulares son distintos en un miembro y en otro y por ello es inexacto comparar como iguales a los miembros de una familia como si todos enfrentaran "la misma situación". (Zuk y Nagy, 1986, p. 37).

\section{c) Chivo expiatorio:}

En el estudio de la interacción familiar, Ackerman distingue tres comportamientos tipo: el papel del destructor y perseguidor, el papel de víctima o de chivo expiatorio y el papel de curandero o "doctor" de la familia. El primero hace uso de prejuicios para canalizar sus ataques contra el chivo expiatorio que al tornarse susceptible es posible de colapso emocional y aparece el miembro sintomático de la Familia (Ackerman en Zuk y Nagy, 1986, p. 73). "El paciente designado acepta a medias su papel 
de chivo expiatorio y sacrifica su autonomía, a fin de llenar las lagunas y vacíos en las vidas de sus padres o en la relación conyugal de éstos, para ajustarse a alguna noción preconcebida por los padres acerca de lo que él debería ser, o para preservar la estabilidad de sus progenitores ... (Aun) cuando prevalecen irrealidades en las mentes de los propios padres, al niño no le queda más remedio que ajustarse a tales irrealidades. Poderosas presiones de culpabilidad e implicaciones de traición o de deslealtad podrán ejercerse sobre el niño, si persiste en su búsqueda de la realidad" (Nagy y Framo, 1988, p. 189),

Entre los significados que se atribuyen al rol del paciente designado se cuentan el de promover la solidaridad del grupo y poner en relieve las reglas y normas y, sobre todo, cumplir su función "mediadora", pues, la presencia de un desviado en la familia puede ser vital para contener la escalada de un conflicto, particularmente entre los padres (Hoffman, 1977, p. 65). Así, el chivo expiatorio viene a ser "la masilla que impide el total alejamiento y separación de los esposos" (Zulliger, 1986, p. 209). Al contar con esta mediación "es posible predecir con certeza casi matemática que cualquier mejoría del paciente se verá seguida por una crisis marital que, a su vez, a menudo hace que reaparezca la patología del hijo" (Watzlawick, 1973, p. 82). A esta reacción del paciente Jackson la llamó "operación de rescate".

\section{d) Simetría y complementariedad:}

Son dos relaciones básicas que suelen complementarse y, como decía Bateson, cada una sirve para contener las tendencias exponenciales de su oponente. La pauta simétrica se guía por la competencia y el cotejo en la búsqueda de quién puede más; cuando esto pasa de cierto límite y pierde el equilibrio ocurre una escalada o escapada simétrica como en las disputas de las parejas que terminan cuando por fin uno de ellos vence o ambos se agotan. Es una lucha entre contendientes y cada uno rechaza al otro en el contenido de su actitud o su mensaje. 
La pauta complementaria es la que en psicoanálisis se conoce como relación sadomasoquista o ligazón de dos formaciones caracterológicas alteradas que se complementan a riesgo de sus propias identidades. Cuando, igualmente, se rompe el equilibrio o se derrumba la relación de complementariedad se produce lo que se ha llamado como "horrenda pareja" (Scheflen), "connivencia" (Laing) o "cisma marital" (Lidz), donde priman progresivos sentimientos de frustración y desesperanza y "sentimientos de extrañamiento y despersonalización, de abulia y acting out compulsivo por parte de individuos que fuera de sus hogares o en ausencia de sus parejas son capaces de funcionar en forma perfectamente satisfactoria" (Watzlawick, 1973, pp. 104-106). Aquí se observa no sólo el rechazo sino también la desconfirmación del self del otro, lo que la hace más patogénica (Hoffman, 1987, p. 74).

Para Jackson, la interacción normal y saludable incluye Secuencias simétricas y complementarias, afirmación que ratifica Watzlawick que las considera cumpliendo "funciones importantes" cuando actúan alternadamente o en áreas distintas, pues aparte de que cada patrón estabiliza al otro, se hace necesario "que los dos participantes se relacionen simétricamente en algunas áreas y de manera complementaria en otras" (ob.cit., p. 104).

\section{e) Pscudomutualidad:}

Wynne hizo hincapié en la "estructura de alineaciones y escisiones", que se produce entre los miembros de la familia. Unos se juntan, se comprenden, comparten y apoyan entre sí, haciendo una relación mutualista; otros se mantienen distantes, desconfiados y prestos a agredirse, en lo que se llama una relación de hostilidad. En las familias con un miembro esquizofrénico, Wynne observó que la alineación entre algunos de sus miembros no era auténtica sino aparente, formal y vacía, además de inestable y falto de intimidad; la denominó "pseudomutualidad". Correspondientemente, la relación escisionista formal y carente de verdadera hostilidad la llamó "pseudo hostilidad". 
En la relación pseudomutual hay excesiva preocupación por aparentar unidad familiar, unanimidad de criterio y diferenciación rígida del resto. Los miembros se valen de diversos medios particularmente mitos e idiosincracias familiares, para lograr esa fachada de "unidad autosuficiente", en cuyo funcionamiento se descubre que no es genuina la alineación o no es clara la intimación, resultando una unidad con "apartheid psicológico". Se cuida mucho de mantener los límites familiares bien separados de los demás, como formando una barrera a la que Wynne puso como nombre "cerca de caucho" o "valla de hule", al parecer flexible, pero en realidad rígida contra todos los de fuera, (especialmente los terapeutas) (Hoffman, 1987, p. 43). Para Searles, la valla de hule sirve a la familia para preservarla de un ego simbiótico que la abarca a toda ella y la defienda de toda individuación o comportamiento divergente (Nagy y Framo, 1988, p. 540), pues esto último descubriría la invalidez de cada miembro por separado.

\section{f) Pseudohostilidad:}

"Los padres vivían en conflicto constante y habían entrado en esa especie, de callejón sin salida al que he llamado pseudohostilidad. Se entiende por esto una defensa compartida contra el reconocimiento o la experimentación de ternura, afecto o atractivo sexual potenciales. Durante veinticinco años, esta pareja había venido hablando de divorciarse, pero nunca se había decidido a hacerlo. El hijo mayor, que era el paciente que presentaba los síntomas, se veía involucrado constantemente en las negociaciones de los padres y la salvación del matrimonio. Esto lo mantuvo en un estado constante de agitación, mezclado con síntomas obsesivos, esquizofrénicos y represivos... En la terapia conjunta con esta familia, advertimos y pudimos comentar la manera en que cada vez que los padres comenzaban a disputar o a expresar sentimientos positivos, se apartaban uno del otro y acudían al hijo mayor. Recíprocamente, él intercedía activamente con enérgicos ataques contra uno u otro, hasta que interrumpían transitoriamente sus disputas o su incipiente hacerse el amor" (Wynne en Nagy y Framo, 1988, pp. 362-363). 
Las expresiones de mutua hostilidad aparecen como una mascarada para ocultar sentimientos positivos que no se quieren reconocer. Este "crónico disputar", dice Boszormenyi-Nagy, es "una de las manifestaciones de una inseparabilidad simbiótica subyacente y, paradójicamente, como canal principal para la expresión de "pertenecer", entre los miembros de la familia" (Nagy y Framo, 1988, p. 96).

\section{g) Proceso de mediación:}

Mediación y mediador aquí no se refieren al proceso de exclusión o desviación que remata en el chivo expiatorio, sino más bien al fenómeno de los sistemas sociales que aparece en el último momento de una situación de conflicto en que es necesario que alguien asuma el manejo de las relaciones en el grupo. Zuk usa los términos mediación y mediador para designar la ubicación del poder en la familia o la aptitud para definir posiciones y controlar las relaciones internas (ob.cit., p. 144). Cuando surge el conflicto, aparecen los "directivos" que desde sus trincheras abanderan las partes rivales y entran en pugna hasta que admiten la necesidad de buscar y seleccionar a quien tenga el poder de mediar para que redefina la naturaleza del conflicto y cambie la posición de los directores permitiendo la continuación de la vida en el grupo primario (Zuk, 1984, p. 127).

La dirección del proceso difiere según sea un miembro de la familia o el terapeuta quien asuma la mediación. Este último buscará el cambio de la familia, mientras que en el primer caso se orientará el proceso para mantener el status quo familiar. Regularmente es la madre quien asume la mediación y ello ya es un indicio de dónde se ubica el poder de la familia. Y no es infrecuente que "en la terapia familiar, no sólo asumen el papel de mediadoras entre su marido y sus hijos, sino también entre éstos y el terapeuta" (Zuk.1984, p. 133).

\section{h) Relación simbiótica:}

Mahler en 1952 repara en la simbiosis; tres años después observa Hill que no es un fenómeno lineal sino de doble sentido, recíproco entre madre 
e hijo. En los sesenta, Bowen afirma que en la simbiosis la amenaza principal para la madre es el crecimiento del niño que rompe el equilibrio de los primeros años de crianza particularmente al llegar a la adolescencia, donde a cada acto que sugiera o prepare la independencia del niño hace reaccionar a la madre que presiona para que el hijo regrese a su posición de impotencia. Haciendo este resumen, Zuk menciona también a Towne, Messinger y Sampson que establecen que el fenómeno no se reduce a la pareja madre-hijo sino que involucra a un tercer miembro cuyo papel es fundamental para el mantenimiento del sistema" (Nagy y Framo, 1988, pp. 29, 33 Y 43). Y así se arma la "fusión" o "unicidad emocional" simbiótica entre los miembros de la familia que comprende fases de intimidad y de distanciamiento. "En las fases de la intimidad emocional, los sistemas intrapsíquicos de los miembros de las familia implicados estaban tan estrechamente fusionados que resultaba imposible distinguir uno del otro. La fusión abarcaba toda la gama del funcionamiento del ego. Un ego podía funcionar por el otro. Un miembro de la familia podía saber con precisión cuáles eran los pensamientos, fantasías, sentimientos y sueños del otro, además podía ponerse enfermo físicamente, como reacción a la tensión emocional del otro ... En las fases del distanciamiento airado, algunos miembros de la familia podían "fusionarse" con otros o con algunas personas que no eran parientes, como los miembros del personal del hospital, y la otra persona se "fusionaba" también en el problema familiar" (Nagy y Framo, 1988, p. 261).

\section{i) Distanciamiento fijo y errático:}

Concepto desarrollado por Searles y Wynne, que recuerda a otros antes vistos como el de pseudomutualidad. Entre los miembros de la familia hay la necesidad profunda de compartir sentimientos entre sí pero al mismo tiempo experimentan el sentimiento de imposibilidad de llegar el uno al otro, representándose recíprocamente que es el otro el que bloquea o impide el apego íntimo. Se plantea la situación familiar de distanciamiento fijo por 
el que los miembros ni se aproximan emocionalmente ni son capaces de separarse y actuar con independencia. "Parecen mantenerse separados por una distancia psicológica más o menos fija" (Wynne en Nagy y Framo, 1988, p. 353). Los sentimientos de intimación se experimentan como si fueran "ingobernablemente amenazadores" y algunas familias excluyen los sentimientos de ira y hostilidad, otras los vinculados con la sensualidad y en otras los sentimientos de ternura y amabilidad. Los miembros viven juntos pero sin hallar sentido a una relación más cercana; comparten actividades pero se hallan emocionalmente desconectados en "una implacable y destructiva fijeza de la distancia en las relaciones así como una manera perseverantemente rígida de organizar los pensamientos y las percepciones" (Nagy y Framo, 1988, p. 352), de modo tal que, por ejemplo, no resuenan a las variaciones de ánimo de un familiar que narra acontecimientos palpitantes.

Una variedad de esta pauta interactiva es el "distanciamiento emocional errático" o formas inestables y cambiantes de establecer "adecuada distancia" entre los miembros. "En un momento se sienten distantes y emocionalmente despegados, y al siguiente, como intrusos o absorbentes" (Ibid., p. 351).

\section{j) Miembros desapegados:}

Interacción que parece ser la antípoda de la relación simbiótica debido a que supone precisamente carencia de "unicidad familiar". Minuchin habla de una organización familiar de "miembros desapegados", donde el problema no es la viscosidad o "proximidad entre los miembros "sino, por el contrario, la incapacidad de los padres para dar respuesta a las necesidades de su hijo" y pone como ejemplo: "la madre no alimenta al bebé en la medida en que sería necesario. Se distrae cuando tiene el niño al pecho o le da el biberón". Vale decir, no se importan los miembros entre sí, hay descuido de unos a otros y no hay signos de interés de uno por el destino del otro (Minuchin y Fishman, 1988, p. 73). Hoffman recuerda otro 
ejemplo de Minuchin para diferenciar entre una familia enredada (fusionada) y una "apartada": "En la primera los padres se alarman si el niño no quiere tomar el postre, y en la última, no se dan cuenta de si no come en todo el día" (ob. cit., p. 83).

\subsection{Otras interacciones:}

Una vez expuestas las interacciones en los tres grupos vistos, se comprende mejor el criterio del énfasis que los distingue, puesto que de la lectura de sus definiciones es deducible que sería intrincado si no imposible por ahora diferenciarlos de otra manera o por otros criterios como por su naturaleza o su esencia. Si bien las denominaciones de las interacciones no se mezclan y hacen posible fijar el énfasis, sus contenidos se cruzan y tienden a imbricarse en muchas de ellas, de modo que no se puede afirmar sin riesgo a equívoco que alguna excluya taxativamente a las otras. El "chivo expiatorio", por ejemplo, encierra buena parte de las interacciones de cada grupo. Es la razón por la cual nos hemos concretado a una mera presentación o descripción rápida de cada interacción, al modo de una caracterización cogida al vuelo y que, además, no se distancia demasiado de lo que se ve en la bibliografía. Cuando en algunas de esas presentaciones añadimos algo más como sus formas de expresión o su motivación lo hacemos sólo para redondear o lograr mejor su retrato.

No se ha intentado una relación de todas las interacciones triádicas familiares, pero se presenta una buena muestra de ellas -diez de cada clase$\mathrm{y}$, precisamente las que son más recurridas en nuestros libros de consulta en razón, asimismo, de que siendo las mayormente citadas, nos ofrecen aquello que en su generalidad vamos a tratar de encontrar en nuestro medio. No sólo no están todas las relaciones triádicas que interesan a la terapéutica familiar sino que también hemos evitado la mención de algunas porque, aparte de no ser citadas a menudo, tienen ciertas particularidades que nos dan licencia para obviarlas, tal como la de sesgar la naturaleza circular de la transacción familiar, según sucede, por ejemplo, con la "sobreprotección materna", que es más diádica y lineal, o la de estar incluidas con evidencia en una interacción ya citada, como la de "alianza intergeneracional" que está contenida en la primera interacción con énfasis en la relación, así como por ser previsible que haya dificultad para su 
captación y registro, como la "alternación" o "defensa interpersonal" de Laing.

Para el interés general que nos mueve, la consideración de treinta transacciones familiares cubre con suficiencia el campo que necesitamos delimitar.

\section{REFERENCIAS BIBLIOGRÁFICAS}

Ackerman y Jackson (970). Teoría y práctica de la psicoterapia familiar.

Buenos Aires: Paidós.

Allport, G. W. (1961). Psicología de la personalidad. Buenos Aires: 1'alOos.

Aramburu y Ponce. (961). Fecundidad, migración y estrategias familiares ... INADEP,

Documento no públicado.

Bateson, G. (1976). Pasos hacia una ecología de la mente. Buenos Aires:

Lohlé.

Benoit, J. C. (1985). Angustia psicótica y sistema parental. Barcelona:

Herder.

Cantoni, F (1984). El dialogo con parejas en conflicto. Lima: Autor.

Fairlie, A. (1992). El circuito punitivo familiar. (Disponible en el IIPs-UNMSM -Facultad de Psicología).

Ferrando, D. y otros (1989). Adolescentes de hoy, padres del mañana.

Bogotá: AGI Presencia.

Haley, J. (1985). Trastornos de la emancipación juvenil y terapia familiar.

Buenos Aires: Amorrortu.

----- (1986). Terapia no convencional. Buenos Aires: Amorrortú.

----- y Hoffman, (1984). Técnicas de terapia familiar. Buenos Aires:

Amorrortú.

Hoffman, (1987). Fundamentos de la terapia familiar. México: FCE.

Laing, R.D. (1974). El yo y los otros. México: FCE.

---- (1977). La política de la experiencia. Barcelona: Crítica.

Minuchin S. (1985). Caleidoscopio familiar. Buenos Aires: Paidós.

----- y Fishman (1988). Técnicas de terapia familiar. Buenos Aires: Paidós.

Nagy y Framo (1988). Terapia familiar intensiva. México: Trillas.

Ponce, A. y otros (1985). Hogar y familia en el Perú. Lima: PUC.

Porot, M. (1962). La familia y el niño. Barcelona: Miracle.

Rotondo, H. (1970). Estudios sobre la familia en su relación con la salud.

Lima: UNMSM.

Watzlawick, P. (1973). Teoría de la comunicación humana. Buenos Aires:

Tiempo Contemporáneo.

Whilaker, C.A. y otros (1990). Danzando con la familia. Buenos Aires: Paidós.

Zuk, G. (1984). Psicoterapia familiar. México: FCE.

----- y Nagy (1985). Terapia familiar y familias en conflicto. México: FCE.

Zulliger, H. (1986). Los niños difíciles. Madrid: Morata. 